\title{
ELECTRICAL AND CHEMICAL CHARACTERIZATION OF CHEMICALLY PASSIVATED SILICON SURFACES
}

\author{
Bhumika Chhabra ${ }^{1}$, Sefik Suzer ${ }^{2}$, Robert L. Opila ${ }^{1}$, Christiana B. Honsberg ${ }^{3}$ \\ ${ }^{1}$ Department of Material Science \& Engineering, University of Delaware, Newark, DE, 19716-3140, USA \\ ${ }^{2}$ Department of Chemistry, Bilkent University, Bilkent, Ankara 06800, Turkey \\ ${ }^{3}$ Department of Electrical \& Computer Engineering, University of Delaware, Newark, DE, 19716-3140, USA
}

\begin{abstract}
The surface composition of chemically passivated silicon substrates is investigated using XPS and FTIR techniques. The samples are passivated with methanol, quinhydrone-methanol and iodine-methanol solution after HF treatment. The minority carrier lifetimes of these chemically passivated silicon substrates are also measured. Quinhydrone-methanol solution provides a chemically inert surface and a considerably longer minority carrier lifetime.
\end{abstract}

\section{INTRODUCTION}

Silicon is the most widely used material for making solar cells due to its mature processing technology and abundance. However, its efficiency is limited by various factors. One of the important factors, particularly as solar cells become thinner, is the surface recombination. The surfaces of the solar cell are sites of particularly high recombination due to the severe disruption of the crystal lattice. Hence measures are needed to reduce the surface recombination which can be achieved by growing a layer on the top of the surface that controls its dangling bonds caused by the disruption of the crystal lattice.

Numerous techniques exist for passivating silicon surfaces, including $\mathrm{SiO}_{2}$, silicon nitride and heterojunctions. Chemical passivation has the advantages that it is simple and low cost to apply and can be performed at room temperature. The goal is to develop a chemical passivation which is stable in air and compatible with other processing steps. In order to develop such a passivation, understanding the impact of the chemical bonding at the surface is very important.

Chemical passivation using iodine-methanol and quinhydrone-methanol has been used previously for temporary passivation and the quinhydrone-methanol is considered to show promising results [1]. This paper presents the minority carrier lifetime comparison of the chemically passivated samples which goes in coordination with the XPS results. A detailed investigation of the chemical changes occurring at the surface using X-ray photoelectron spectrometer (XPS) for methanol, quinhydrone-methanol and iodine-methanol treated samples is presented. Furthermore, the same substrates are used to study the $\mathrm{Si}-\mathrm{H}$ bonding at the surface using Fourier Transform Infra Red (FTIR).

\section{EXPERIMENTAL}

The samples reported here are n-type phosphorus doped Si substrates with $\langle 1-0-0\rangle$ orientation. The resistivity is $100 \mathrm{ohm}-\mathrm{cm}$, double side polished, $475+/-25 \mu \mathrm{m}$ thick $\mathrm{FZ}$ wafers. The wafer cleaning includes wet chemical oxidation in $\mathrm{H}_{2} \mathrm{O}_{2}: \mathrm{H}_{2} \mathrm{SO}_{4}$ (1:4) solution for five minutes followed by 5 minutes dip in $5 \% \mathrm{HF}$ solution. For this work, the concentration of quinhydrone in methanol is $0.01 \mathrm{~mol} / \mathrm{L}$ and that of iodine in methanol is $0.09 \mathrm{~mol} / \mathrm{L}$. The suitable range of concentration of quinhydrone in methanol is between 0.01 to $0.05 \mathrm{~mol} / \mathrm{L}$ for passivation [1].

We used the WCT-120 Lifetime Tester [2] with the light source power of $60 \mathrm{~W}$ and the calibrated injection range of $10^{12}$ to $10^{16} \mathrm{~cm}^{-3}$ for the lifetime measurements. XPS spectra are recorded using a PHI 5600 X-ray photoelectron spectrometer equipped with a monochromatic aluminum K- $\alpha$ X-ray source and a hemispherical electron energy detector. Spectra are recorded using a 45 degree takeoff angle. The samples are also analyzed using a Bruker Tensor 20 FTIR spectrometer.

\section{RESULTS \& DISCUSSION}

\section{(I) Lifetime Measurements}

The Surface Recombination Velocity $\left(S_{r}\right)$ is an important parameter that specifies the recombination at the surface. It can be deduced from the minority carrier lifetime measurements using the following equation [3].

$$
\frac{1}{\tau_{\text {eff }}}=\frac{1}{\tau_{b}}+\frac{2 S}{W}
$$


$\tau_{b}$ is assumed to be infinite in Eq. 1 for calculating the surface recombination velocity.

The lifetime is measured from the photoconductance decay of the substrate with the excess carriers generated due to the light pulse using the WCT120 Lifetime Tester. The injection level used for all the lifetime measurements shown in Table 1 is $1 \mathrm{e}^{15} \mathrm{~cm}^{-3}$.

\begin{tabular}{|c|c|c|}
\hline $\begin{array}{l}\text { Chemical } \\
\text { Treatment }\end{array}$ & $\begin{array}{l}\text { Effective } \\
\left.\text { Lifetime ( } \zeta_{\text {eff }}\right) \text { at } \\
1 \text { e15 } \mathrm{cm}^{-3} \& \\
\text { Surface Rec. } \\
\text { Velocity }\end{array}$ & $\begin{array}{l}\text { Eff. Lifetime } \\
\text { out of } \\
\left.\text { solution ( } \zeta_{\text {eff }}\right) \\
\text { at } 1 \text { e15 } \mathrm{cm}^{-3} \\
\text { varying with } \\
\text { time }\end{array}$ \\
\hline $\begin{array}{l}\mathrm{H}_{2} \mathrm{O}_{2}: \mathrm{H}_{2} \mathrm{SO}_{4} \& \\
\mathrm{HF} \text { clean only }\end{array}$ & $\begin{array}{l}125 \mu \mathrm{s} ; \\
184 \mathrm{~cm} / \mathrm{sec}\end{array}$ & $\begin{array}{l}62 \mu s \\
\text { (after } 12 \mathrm{hrs} \text { in } \\
\text { air) }\end{array}$ \\
\hline $\begin{array}{l}\mathrm{H}_{2} \mathrm{O}_{2}: \mathrm{H}_{2} \mathrm{SO}_{4} \& \\
\mathrm{HF} \text { clean; } \\
\text { Methanol } \\
\text { passivated }\end{array}$ & $\begin{array}{l}76 \mu \mathrm{s} \\
302 \mathrm{~cm} / \mathrm{sec}\end{array}$ & $\begin{array}{l}37 \mu s \\
\text { (after } 12 \mathrm{hrs} \text { in } \\
\text { air) }\end{array}$ \\
\hline $\begin{array}{l}\mathrm{H}_{2} \mathrm{O}_{2}: \mathrm{H}_{2} \mathrm{SO}_{4} \& \\
\mathrm{HF} \text { clean; } \\
\text { QHY/ME } \\
\text { passivated }\end{array}$ & $\begin{array}{l}2.2 \mathrm{~ms} ; \\
10.4 \mathrm{~cm} / \mathrm{sec}\end{array}$ & $\begin{array}{l}819 \mu \mathrm{s} \\
\text { (after } 24 \mathrm{hrs} \text { in } \\
\text { air) }\end{array}$ \\
\hline $\begin{array}{l}\mathrm{H}_{2} \mathrm{O}_{2}: \mathrm{H}_{2} \mathrm{SO}_{4} \& \\
\mathrm{HF} \text { clean; } \\
\mathrm{I}_{2} / \mathrm{ME} \\
\text { passivated }\end{array}$ & $\begin{array}{l}894 \mu \mathrm{s} ; \\
25 \mathrm{~cm} / \mathrm{sec}\end{array}$ & $\begin{array}{l}68 \mu \mathrm{s} \\
\text { (after } 24 \mathrm{hrs} \text { in } \\
\text { air) }\end{array}$ \\
\hline
\end{tabular}

Table 1. Minority carrier lifetime values and surface recombination velocities of the chemically passivated samples.

Four samples used for lifetime measurement were cleaned using the cleaning process described in the experimental section of this paper. The first sample in the table is only $\mathrm{H}_{2} \mathrm{O}_{2}: \mathrm{H}_{2} \mathrm{SO}_{4}$ and $\mathrm{HF}$ clean i.e. the sample was taken out of HF and dried with dry nitrogen gas for measurement. In general, the lifetime value measured while the sample is in HF solution is very high [4]. The second sample is dipped in Methanol, the third sample in Quinhydrone-Methanol and the fourth in iodine-methanol after the standard cleaning process. All the samples except the first one were kept in the respective solutions for approximately one hour passivation and measured while they were still in solution. Afterwards, the samples were taken out of the solution and dried with dry nitrogen gas for measuring the lifetime after $12 \mathrm{hrs}$ for HF clean and methanol passivated and after $24 \mathrm{hrs}$ for quinhydrone/methanol and iodine/methanol passivated sample.

Table 1 shows the comparison of minority carrier lifetimes in and out of the solution. As can be seen, the lifetime measurements indicate that the quinhydronemethanol solution passivates the surface best giving a very high minority carrier lifetime of $2.2 \mathrm{~ms}$ at $1 \mathrm{e} 15 \mathrm{~cm}^{-3}$ and a low surface recombination velocity of $10.4 \mathrm{~cm} / \mathrm{sec}$. The methanol, quinhydrone-methanol and iodine-methanol samples retain their effective lifetime values as long as the sample is in the solution. While as expected, the lifetime of all the samples decreased substantially after they were exposed to air with varying times. These results are consistent with the XPS study which show that the bonds formed in the quinhydrone-methanol solution passivates the surface of the silicon.

\section{(II) XPS Study}

In a previous paper the surface composition of iodine-methanol passivated silicon substrates was measured using XPS, where results suggested that this process led to methoxy-terminated surfaces [5]. However, while iodine-methanol passivation provides good surface passivation, it is not stable. Hence, the main goal of our study is to examine correlation(s) between surface passivation and stability and chemical composition.

We performed XPS measurements to characterize the chemical composition of the Si surfaces before and after various passivation schemes (Hterminated surface, methanol, quinhydrone-methanol and iodine-methanol). In Fig. 1 we show the C1s regions of two samples which were immersed in the reference methanol (upper graph) and quinhydrone-methanol (lower graph) solutions for $1 \mathrm{hr}$ duration. These samples were exposed to air for more than 12 hours and XPS measurements were taken.

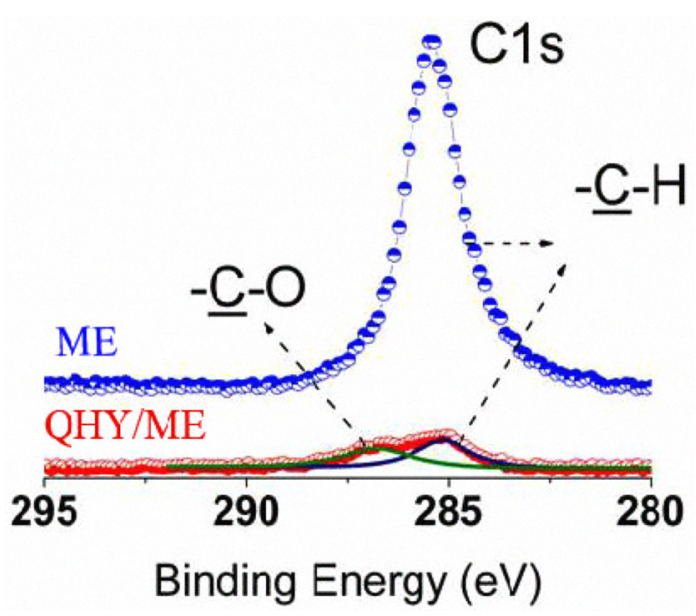

Fig. 1. C1s regions of the XPS spectra of two samples. Top spectrum is for sample introduced into the methanol solution and the lower one is for the surface passivated with quinhydrone-methanol solution after an initial HF cleaning process. Note that the absence of contamination on the quinhydrone-methanol passivated sample. 
The C1s spectrum of the quinhydrone-methanol surface indicates the presence of $\mathrm{O}-\mathrm{CH}_{\mathrm{y}}$ groups bonded to $\mathrm{Si}$. The H-terminated $\mathrm{Si}$ sample exposed to methanol solution has a large hydrocarbon peak at $285.0 \mathrm{eV}$ in contrast to the quinhydrone-methanol sample. This hydrocarbon is typical of the adsorption of adventitious carbon from the ambient after removing a Si-surface from the HF dip. It is remarkable that the quinhydronemethanol surface remains relatively free of carbon contamination after 12 hours.

The C1s spectrum shows that the quinhydrone has reacted with the silicon surface, and that the electro phobic $\mathrm{H}$-terminated surface found in methanol solution has adsorbed a large amount of adventitious carbon.

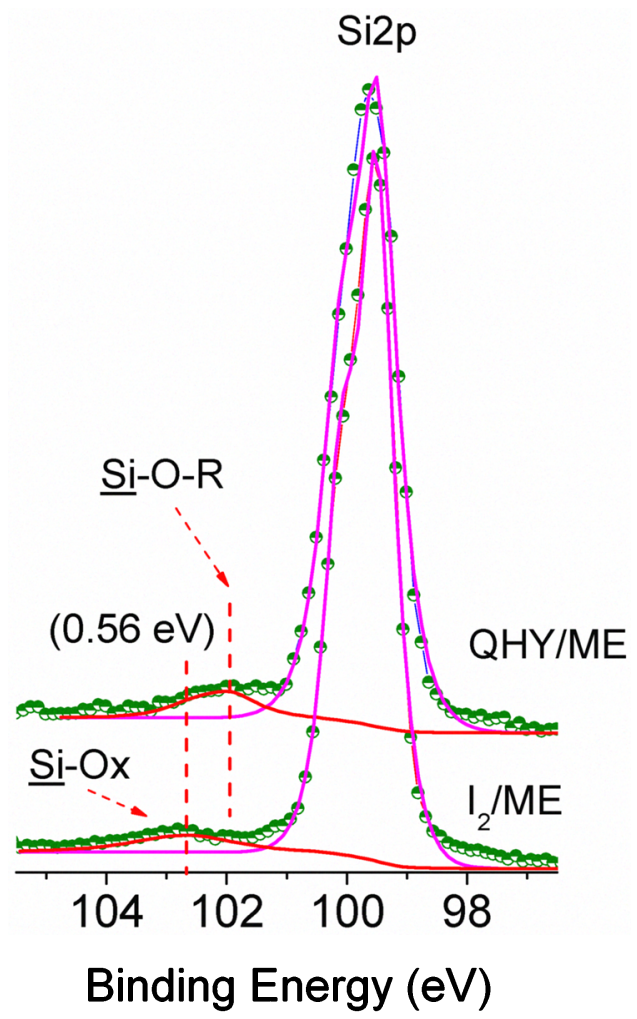

Fig. 2. Si2p, Si-O-R and Si-Ox regions of the XPS spectra of the two samples. The top spectrum is for Quinhydronemethanol passivated sample and the lower spectrum is for lodine-methanol passivated sample. It is consistent with QHY/ME passivates the surfaces better than $\mathrm{I}_{2} / \mathrm{ME}$.

XPS measurements of the Si $2 p$ region were also taken for samples passivated in iodine-methanol and quinhydrone-methanol solution. The concentration of iodine in methanol is $0.09 \mathrm{~mol} / \mathrm{dm}^{-3}$. Fig. 2 shows a more intense SiOx feature in the case of $\mathrm{I}_{2} / \mathrm{ME}$. A more intense sub-oxide peak which can be attributed to Si-O-R appears in the case of QHY/ME as shown in Fig. 2. This result suggests that the quinhydrone-methanol passivated sample oxidizes less than the iodine-methanol, probably due to the formation of stable O-R groups.

A clean silicon sample gives a spin-orbit split doublet Si $2 \mathrm{p}$ peak at $99.6 \mathrm{eV}$, and any oxidation results in appearance of additional peaks at higher binding energies. Analyses of the spectra displayed in Fig. 1 reveal the presence of small peaks at 102.0 and $102.6 \mathrm{eV}$ for the quinhydrone and iodine passivated samples, respectively. The Si $2 p$ peak of a fully oxidized silicon corresponding to $\mathrm{SiO}_{2}$ should appear at around $103.2 \mathrm{eV}$, but silicon bonded to oxygen and an organic group (i.e. Si-O-R, where $-R$ represents a hydrocarbon moiety) and underlying $\mathrm{Si}$ atoms would have a Si 2p binding energy at around $102.0 \mathrm{eV}$ [5]. Accordingly, we are tempted to interpret the surface composition of the quinhydrone treated sample to contain partially oxidized Si-O-R groups where $\mathrm{R}$ is most likely to be a $-\mathrm{CH}_{3}$ group incorporated from the solvent methanol. On the other hand, the $0.6 \mathrm{eV}$ higher binding energy of the iodine-treated sample surface is best interpreted as containing more highly oxidized, but still suboxide SiOx groups. This interpretation is also consistent with our FTIR findings, discussed below.

\section{(III) FTIR Study}

FTIR is being used to follow up the chemical changes in the $\mathrm{Si}-\mathrm{H}$ bonding around $2100 \mathrm{~cm}^{-1}$ before and after passivation schemes. Quinhydrone is a mixture of Benzoquinone and Hydroquinone components which absorb at around 250 and $300 \mathrm{~nm}$ respectively.

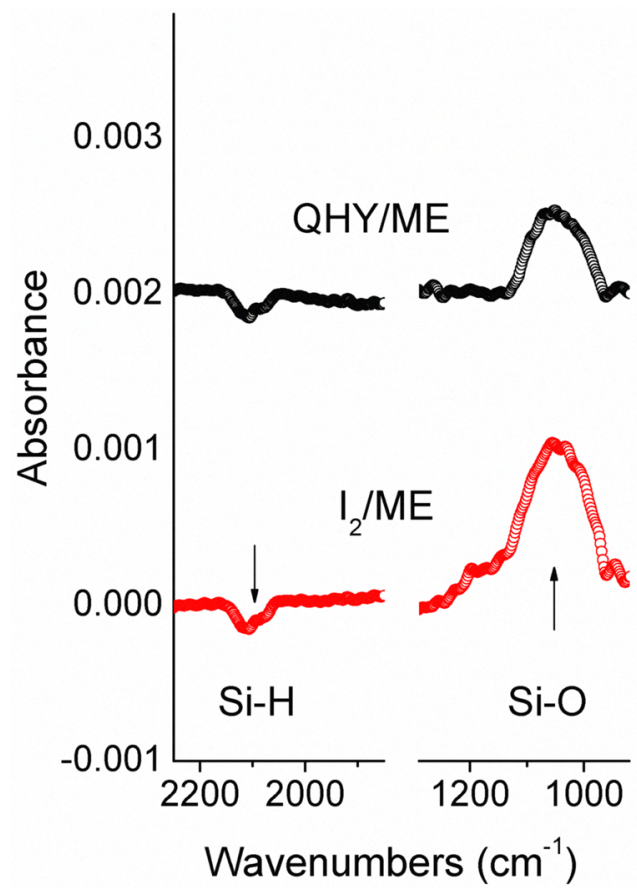

Fig. 3. FTIR study showing Si:H and Si-O peaks for QHY/ME and $I_{2} / M E$ passivated samples. 
An IR spectrum of a hydrogen terminated silicon surface after proper HF treatment contains $\mathrm{Si}-\mathrm{H}$ stretching peaks around $2100 \mathrm{~cm}^{-1}$. These peaks diminish rapidly after exposure to air, which is a clear indication of the sites where oxidation process starts. These $\mathrm{Si}-\mathrm{H}$ peaks/features in the spectra are usually very weak (0.0001-0.001 absorbance units), hence care has to be exercised to record the corresponding changes properly.

In Fig. 3, we show the FTIR spectra recorded after the passivation procedures, where the sample cleaned after HF treatment but before passivation is used as the background for recording the FTIR data. Examination of the figure clearly reveals that both of the passivation routes yield consumption of the $\mathrm{Si}-\mathrm{H}$ bonds (appearing as negative going features) and Si-O bonds growing as evidenced by the peaks around $1100 \mathrm{~cm}^{-1}$. It is worth mentioning that both $\mathrm{Si}-\mathrm{O}-\mathrm{Si}$ and Si-O-R stretching frequencies appear around $1100 \mathrm{~cm}^{-1}$. Hence, a clear-cut distinction between the two bonds is not possible on the basis of the IR peaks observed. One thing is clear, however, that when compared with the quinhydrone passivated sample, the extent of oxidation is higher in the iodine-case. FTIR are consistent with XPS, with results indicating that the resulting oxidation of the quinhydronemethanol passivation is milder when compared with the iodine-methanol case.

\section{CONCLUSIONS}

A detailed investigation of the chemical changes occurring at the surface for methanol, quinhydronemethanol and iodine-methanol treated samples has been done. A very high minority carrier lifetime value of $2.2 \mathrm{~ms}$ at $1 \mathrm{e} 15 \mathrm{~cm}^{-3}$ is obtained with a low surface recombination velocity of $10.4 \mathrm{~cm} / \mathrm{sec}$. It is shown with XPS and lifetime measurements that the quinhydrone-methanol passivates the silicon surface by reducing oxidation as compared to iodine-methanol. FTIR study also explains that quinhydrone-methanol sample is subjected to less oxidation as compared to iodine-methanol passivated sample.

\section{REFERENCES}

[1] Hidetaka Takato, Isao Sakata and Ryuichi Shimokawa, "Surface Passivation of silicon substrates using Quinhydrone/methanol treatment", $3^{\text {rd }}$ World Conference on Photovoltaic Energy Conversion, 2, pp. 1108-11 (2003).

[2] R.A. Sinton, A. Cuevas, and M. Stuckings, "QuasiSteady-State Photoconductance, A New Method for Solar Cell Material and Device Characterization," Proc of the 25th IEEE Photovoltaic Specialists Conference, pp. 457460, 1996.

[3] M. J. Kerr and A. Cuevas, "Very Low Bulk and Surface Recombination in Oxidized Silicon Wafers" Semi. Sci. and Tech., 17, pp. 35-38, (2002).
[4] M. J. Kerr, Ph.D. Thesis, Australian National University, "Surface, Emitter and Bulk Recombination in Silicon and Development of Silicon Nitride Passivated Solar Cells", (2002).

[5] Renee T. Mo, Tracey A Burr, Gregory T. Merklin, Francisco Machuca, Piero A. Pianetta, Lionel C. Kimerling, Ronald P. Chiarello and Christopher E.D. Chidsey, “ Atomic-Sacle Mechanistic Study of lodine/Alcohol Passivated SI (100)", $196^{\text {th }}$ Meeting of the Electrochemical Society, SLAC-PUB-8262, Sep (1999).

[6] Briggs, D., Seah, M. P. "Practical Surface Analysis, Vol. I", $2^{\text {nd }}$ Ed. Wiley, Chichester (1990). 